\section{Cartography of a Pedagogical Experience: Architecture as a (In)Discipline in Process}

\section{Maria Júlia Barbieri}

Pontifícia Universidade Católica de São Paulo

This article focuses on the experience of teaching and teaching-learning relations with a focus on the creative processes in the Architecture and Urbanism Course, more specifically in a curricular unit of Architecture Design. The reflection proposed here takes into account the body-environment relationship as a methodological matrix for teaching and investigates the way in which students understand, interpret and act from their own body's experiences in space. The theoretical subsidies that support this approach are related to the studies of cognition, mainly from the perspective of the embodied mind theory developed by VARELA, THOMPSON, \& ROSCH (1992) in addition to JOHNSON (2007) and his theory of meaning-making, and studies developed by KASTRUP (1999) in his theory of inventiveness. We seek in these theorists the possibility of weaving a discussion that understands the process of creation as an unceasing movement of exchanges between the body and the environment. In this sense, we developed and applied a methodology that aims to explore different experiences of the body in space as mediators of the creative process in architecture. Removing students from the closed space of the classroom, getting them out of chairs and desks and returning the movement to the bodies and the rediscovery of environmental perceptions is the starting point for this methodology developed in the light of CARERI's drift theory (2013). The drift gains a very valuable sense here, since by launching the body into space in search of unexpected encounters, we are exploring the powers of this encounter so that students can make this event a fertile field for the creation process, returning them to the fecund environment of discovery as opposed to the sterile space of the classroom. The (in) disciplinary character of this methodology, in the most radical sense of transdisciplinarity, makes the body and space have their blurred limits, and can thus co-evolve in motion, giving rise to creative processes, in which students they invent themselves at the same time as they invent the world in which they learn. All cartographies developed in the student creation processes in this course are presented on the social network Instagram, where the work teams share their processes, appropriating the tools and languages specific to this media.
KEYWORDS

Architecture, body, Environment, Creation process, Teaching-learning 